\title{
Innovative Graphing Skills Through Interrogation of Silent Ingredients
}

\author{
$\underline{\text { https://doi.org/10.3991/ijet.v15i12.11675 }}$
}

\author{
Muad M. Shiyyab \\ Yarmouk University, Irbid, Jordan \\ muad@yu.edu.jo, muadhh@yahoo.com
}

\begin{abstract}
All of the pre-service mathematics teachers had their undergraduate education in mathematics, but are unfamiliar with some topics and skills that are central and foundational to mathematics. Thus, these teachers often lack the knowledge and skills to teach one of the discipline's most difficult topics that are becoming increasingly mandated in local curricula and central to understanding mathematics. This lack of knowledge and skills supplicates supportive and flexible skills and approaches that teachers can use not only to introduce but also to learn difficult subject matters. Graphing functions is one such a difficult topic that has been the jurisdiction of the secondary as well as college mathematics. But is now on the agenda of research given its important role in understanding mathematical functions. In the present study, I introduced 33 (31 male and 2 female) pre-service mathematics teachers to two methods for graphing functions through interrogating of function's silent feature and ingredients to develop function sense and graphing skills. Pre-service teachers' feedback, understanding, and growth in terms of their knowledge and skills in graphing as a result of learning these two methods were observed, reported and analyzed qualitatively. This showed positive progress in the learner's ability, disposition, and skills in graph functions and understand interrelationships through meaningful schema. Also, it gives rational and logical reasoning for mathematical phenomena such as concavity, and issues related to the limits of a function.
\end{abstract}

Keyword - Graphing skills, pedagogy of mathematics, silent features, specialized content knowledge

\section{Introduction and Literature Review}

Mathematics educationalist proposes and tries several approaches for the advancement of understanding topics that students have trouble understanding and making sense of them. Sriraman and English [1] have explained the importance of the embodied cognition theory for understanding mathematics. Several researchers [2], [3], [4], [5], [6], [7] also have introduced and tried the role of metaphors for teaching and learning mathematics. Besides, exposing students to real-life situations and activities is a part of realistic mathematics education which had shown significant positive contribution to the development of student's competence [8], where contextual activities and use of technology whether through computer or tablet, mobile technology; smart 
mobile devices are imperative tools for penetrating mathematical phenomena [9], [10], [11], [12], [13], and a form of heuristic thinking for solving a problem [14].

Research has shown that improving the ability to gestalt the graph for an algebraic function is an extremely important component for developing functional sense [15]. However, this could be achieved by making sense of the smaller components of the concept or function and the interrelationships between its components. Part of the process of the conceptual development is not only tying between algebraic representation and graphical one at the procedural level, but also to help students think of the concept visually to interpret, and explain algebraic manipulations, where concept is defined as "a convenient capsule of thought that embraces thousands of distinct experiences and that is ready to take in thousands more" [16]. Encapsulation by itself could be seen as a sub-goal that must take place as a crucial process for building the concept itself. Encapsulating is defined as the process of grasping how the fine pieces of a complex function upshot each other through operations whether division, composition or any other form of transformation. Encapsulating object and action together lead to what Piaget called "Pseudo empirical abstraction". Where objects could be fine ingredients of phenomena, and where action refers to the impact caused by an operation. Graphing power and skills are the productions of logico-mathematical thinking and construction that students need to build to be able to logically draw and interpret functions. The notion of reflective abstraction that [17] had introduced to describe the level of understanding had stimulated others to farther describe learning. Their description led to the development of APOS (Action, process, Object, Schema) theory and its role in helping learners learn mathematic better [18]. In this theory, the concept of genetic decomposition model was introduced to describe how learner might be able to learn a mathematical concept, where genetic decomposition refers to "a hypothetical model that describes the mental structure and mechanisms which a student might need to construct to learn a mathematical concept"[18]. In the same metaphoric analogy, we can ask the question "what student need to learn to develop the ability to model or graph phenomena or complex function?". Moreover, what is the nature of the logical-mathematical structure student need to build?. Research identifies five types of construction involved in building the learner's logical thinking, namely: encapsulation, interiorization, coordination, generalization, and reversal.

Encapsulation itself takes different levels; encapsulation of object and action, encapsulation of the impact of action upon action, or as Piaget called it "a reflective abstraction where the concern is about interrelationships among actions" [19]. For example, in graphing the curve for $f(x)=\ln \left(\frac{\cos x}{x}\right)$, one needs to imagine the impact of the division process; dividing the values of the $y=\cos x$ which vary between [$1,1]$ by the values of the function of $y=x$ as it increases and takes the values between $[-\infty, \infty]$. Then, thinking of how to apply the $(\ln )$ would make its impact on the impact caused by the division processes. The ability to imagine such an impact is crucial for building logico-mathematical construction. Moore argues that the nature of the skills must be developed to build non-superficial knowledge should be creative in nature, that is, skills such as creative imagination, creative judgment, and creative thinking skills, etc., [20]. In the same context, the graphing phenomenon is a process of expressing meaning embodied in the mental image for given phenomena or a func- 
tion. It is argued that mental representation helps the learner to embody meaning in imagery form [21]. This could explain why students are not able to graph a function or model; their inability could reflect some type of deficit in understanding concepts, such as rate of change, meaning of the impact of positive or negative derivatives in imagery or visual forms, where student understanding is restricted into algebraic symbols and signs, and detached from realizing the leverage on the graphing process. Realizing the impact comes through interiorizing the action and coordination that comes as a consequence of what is considered as an object, such as the impact of the positive derivatives (whether first or second one) in producing a graph. The possible advantages of drawing a graph and alternative representations are: first, alternative representation helps relieve the learner from relying on manipulation to operate mathematically at the reflective abstraction level. Second, they help improve situated learning where learners can better use mathematical knowledge to interpret real-life phenomena and realistic mathematics to better understand the attribute of mathematical concepts [8] such as graphs and graphing. Third, they improve heuristic thinking particularly by modeling, classifying, comparing and controlling different representations. Fourth, they help learners to form a schema which includes complex interrelationships between objects, actions, the impact of the object on objects and actions, possible impact among objects and actions [21].

\section{The Problem}

The researcher noticed alarming weakness among students in graphing functions and modeling real-life phenomena. Students at the undergraduate, and graduate-level were given several functions to sketch graphs for them. One of the functions that were given to students was $f(x)=\ln \left(\frac{\cos x}{x}\right)$. Students were asked to give an estimate or rough sketch to the function and provide reasoning for their drawing. Figure 1 through figure 5 are samples of their responses. Many students did not draw any sketch and did not provide reasoning. Their weakness could reside in the deficit to interpret and translate the signs of the derivatives into actions, processes, and graphs. Their inability to graph functions could be hypothesized as a no-understanding of the meaning or consequences of the positive and negative first and second derivatives; this is because they did not attempt to find the first and second derivative, which could be hypothesized as unawareness of the nature of the interrelationships among the components of the function. The action or impact of division of the function $f(x)=\cos x$ on the action created by $g(x)=x$, was not understood by them as they could not understand the role of the function $(\ln )$ may impact $\left(\frac{\cos x}{x}\right)$. In an epistemology where learning is viewed as reflective abstraction in the context of schemes theory, their weakness could be explained as the absence of coordination among object, action, and operation. The misconception of the interrelationships between action and action is evident in students' sketches. In our case, the objects are $\cos x, x, \ln$, and $\ln \left(\frac{\cos x}{x}\right)$. Moreover, the impact of the inter-relationships of every function must be seen as a dynamic action too. 
Paper-Innovative Graphing Skills Through Interrogation of Silent Ingredients

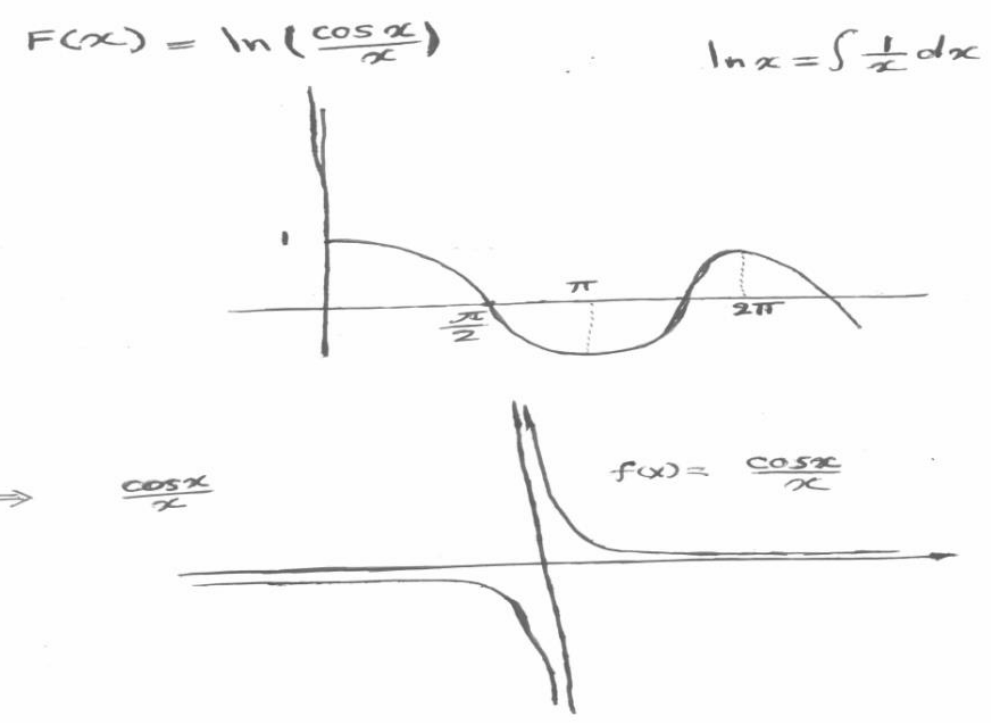

Fig. 1. Student's sketch for $y=\ln \left(\frac{\cos x}{x}\right)$
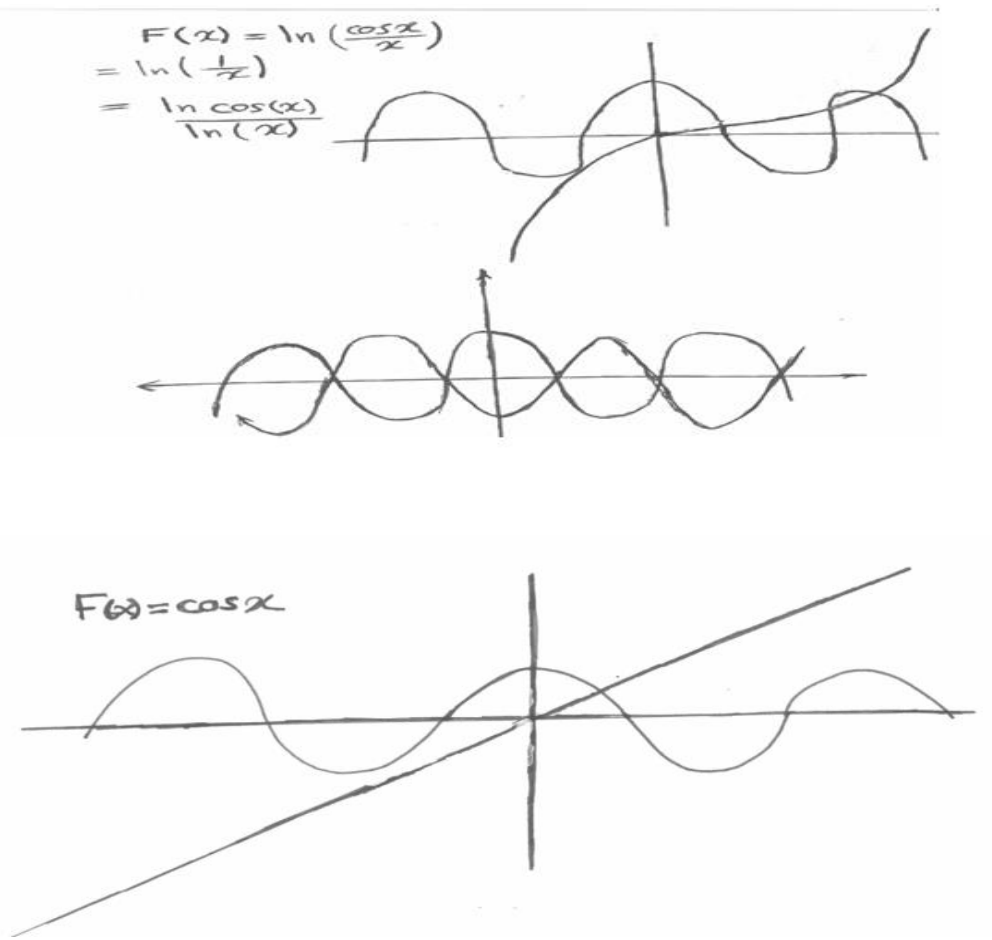

Fig. 2. Student's sketch for $y=\ln \left(\frac{\cos x}{x}\right)$ 


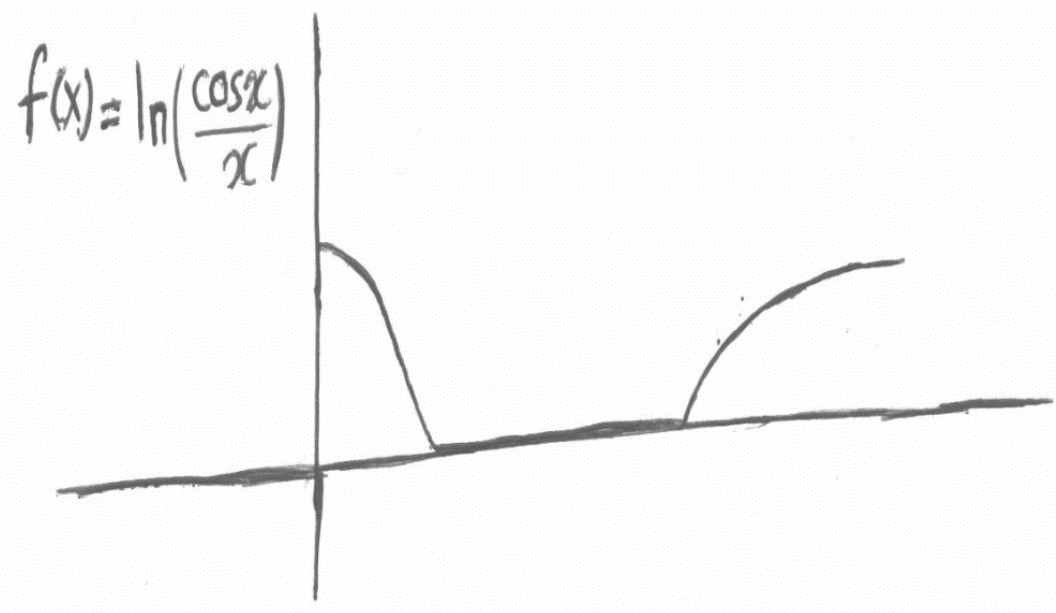

Fig. 3. Student's Sketch for $y=\ln (\cos x / x)$

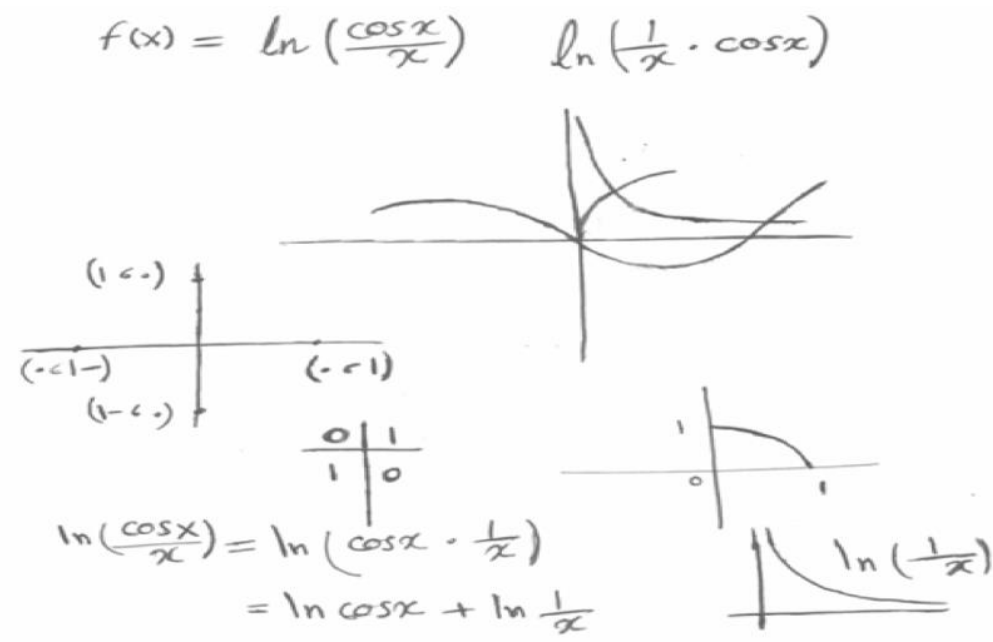

Fig. 4. Student's sketch for $y=\ln \left(\frac{\cos x}{x}\right)$ 


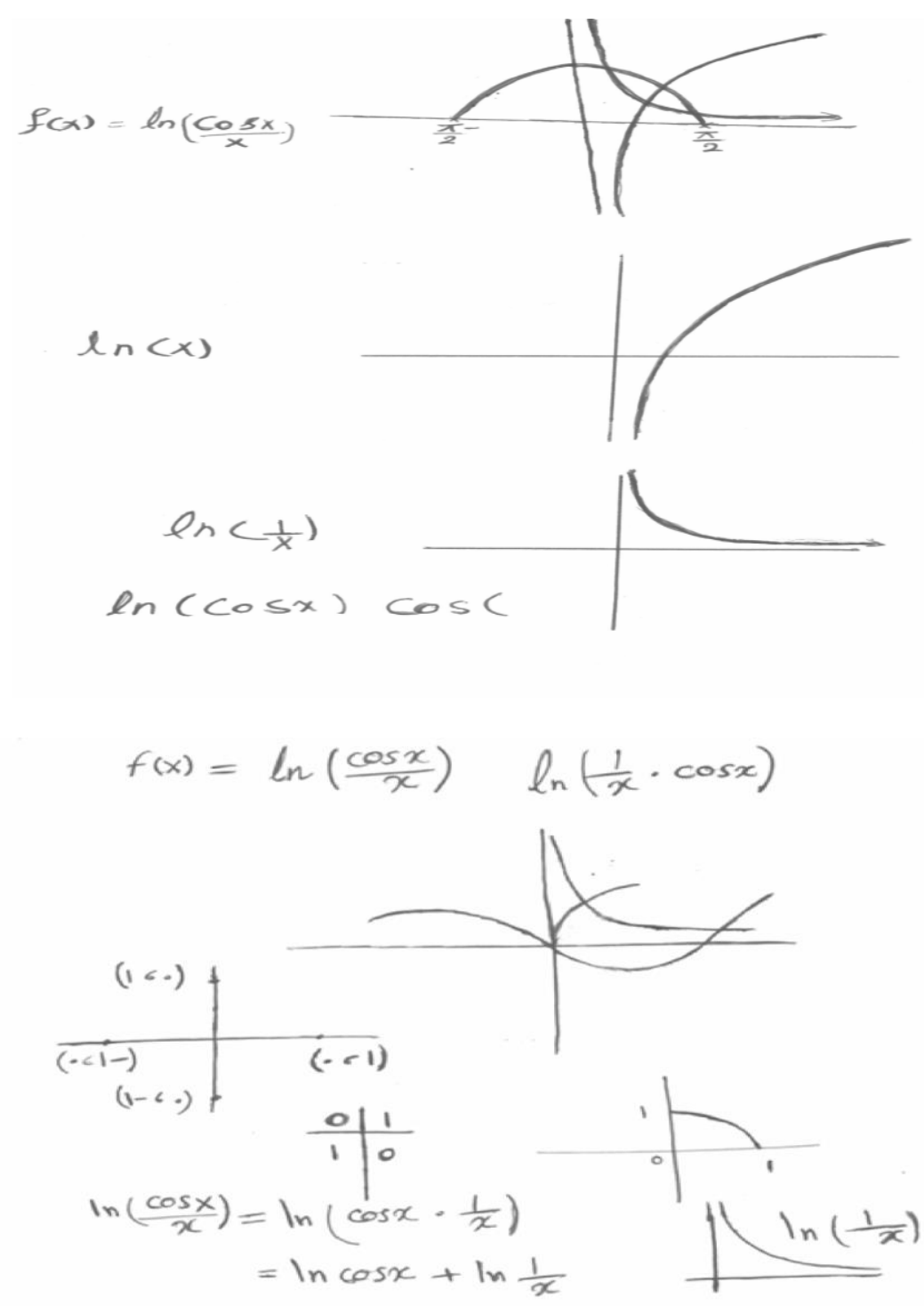

Fig. 5. Student's sketch for $\mathrm{y}=\ln \left(\frac{\cos x}{x}\right)$

\section{$3 \quad$ Method}

\subsection{Research design and participants}

This is an exploratory study that aims to describe and analyze the impact of the interrogation of the silent features approach in developing the ability and disposition of 
the student regarding graphing mathematical functions. Data was collected through observing and interviewing students who were asked to graph several functions. The sample consisted of 33 students who have already completed their undergraduate degree in mathematics. 31 of them were enrolled in their master's degree in mathematics education program, 2 female students had a master's degree in mathematics and already enrolled in the mathematics education doctoral program.

\subsection{Instrument}

A set of functions were used to assess the participant's ability and disposition to draw graphs based on the non-conventional way of thinking through interrogating silent features and interrelationships among the components of the given functions. Among the functions that were given to students are the following four functions

Table 1. The four functions were given to students to graph.

$$
\begin{aligned}
& f(x)=\ln \left(\frac{x^{4}-1}{x^{3}}\right) \\
& f(x)=\cosh x \\
& f(x)=\ln \left(\frac{\sin x}{x}\right) \\
& f(x)=\ln (\sec x / x)
\end{aligned}
$$

The participant's reaction and responses before and after the "method of interrogation of silent features for graphing functions" were explained and then was observed and analyzed qualitatively.

\subsection{The Procedure}

In the first part of the meeting, students were given a set of functions to graph them and provide a rationale for their arguments and graphs. Students' responses whether written or oral were recorded. In the next step, my method (interrogation of silent features) was explained interactively. This is based on interrogating of silent features to make sense of the function through reflecting and analyzing the nature of the functions by examining its components and the interrelationship among them and investigating their impact on the graph as a whole.

Step1: The researcher wrote on the board "Graph $f(x)=\ln \left(\frac{x^{2}-1}{x^{3}}\right)$. Students were given time to try to sketch a rough graph individually and cooperatively.

Step2: To model my method I wrote $f(x)=\ln \left(\frac{\cos x}{x}\right)$ on the board. Then, I explained my method of interrogating silent ingredients or features through reflection, analyzing, and then drawing through thinking allowed. Students were asked to give reasoning and interpretation for every single piece of information and step.

The following account describes the method of interrogation of silent ingredients: the cosine of $x$ divided by $x$, and $(\ln )$ was applied to the figure resulted from the 
division process. So, the silent feature is a division process. Then, $f(x)=\cos x$, and $g(x)=x$ were drawn separately on the same plane (figure 6).

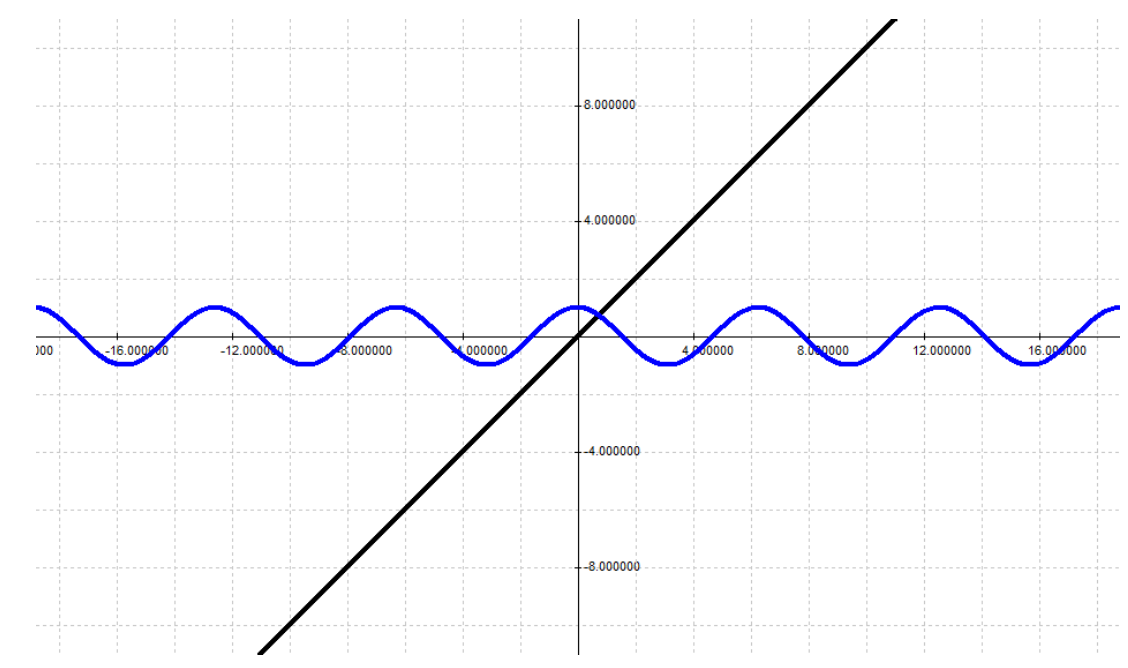

Fig. 6. $y=x$, and $y=\cos x$.

The division process was started. At $x=0$, the value of the $\cos x$ is 1 , but the value of $y=x$ at $x=0$ is 0 . This means that when we divide by 0 , we must go to infinity. This is because approaching 0 from the right side, we will be dividing positive values by positive values). On the contrary, approaching 0 from the left we will be dividing positive values of the $\cos x$ in $\left(0, \frac{\pi}{2}\right)$ by the negative values $(y=x$ is negative at negative $x-$ axis). This means that the values of the $\cos x$ divided by $x$ will be negative as we get closer to $x=0$ from the left. Hence, the values of the rational function $(\cos x / x)$ will go to minus infinity. In addition, the value of the quotient $(\cos x / x)$ will be 0 at $x=\frac{\pi}{2}$ (it is $\left.0 / \frac{\pi}{2}=0\right)$. Now, in the interval $\left(\frac{\pi}{2}, \frac{3 \pi}{2}\right)$ the cosine is negative and the values of $y=x$ are positive, so negative divided by positive is negative. At $x=\frac{3 \pi}{2}$ the value of the quotient will be 0 , but in between the minimum value will be at $x=\pi,\left(\frac{\cos \pi}{\pi}=\frac{-1}{\pi} \approx \frac{-1}{3}\right)$. So, the graph in this interval will take the shape of the cosine, but with a lower wave height $\left(\left(\approx \frac{-1}{3}\right)\right.$. To determine the height of the wave, another silent feature should be investigated; it is the function of $\left(-\frac{1}{x}\right)$, and the function $\left(\frac{1}{x}\right)$ (figure 7$)$. 


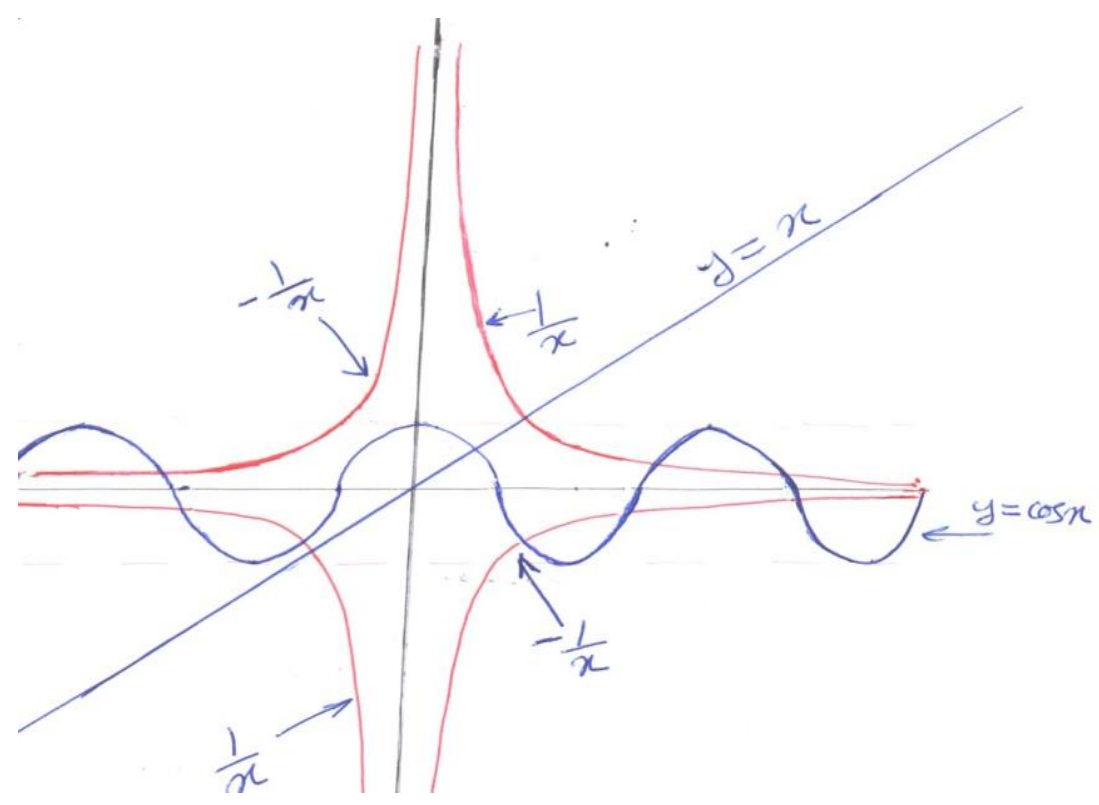

Fig. 7. $y=x, y=\cos x, y=1 / x, y=-1 / x$

They are floor and ceiling for $\frac{\cos x}{x}$ respectively $\left(-\frac{1}{x} \leq \frac{\cos x}{x} \leq \frac{1}{x}, x>0\right)$, whereas, the opposite is true on the negative $x$ - axis (i.e. $\left(\frac{1}{x} \leq \frac{\cos x}{x} \leq \frac{-1}{x}, x<0\right)$. Hence $\left(-\frac{1}{x}\right)$ is the ceiling, and $\left(\frac{1}{x}\right)$ is the floor. The division process will continue in the same fashion to yield a graph (figure 8) similar to that of the cosine, with the exception related to the heights of the wave, where the height of the wave decreases or depreciates as $x$ goes to infinity and minus infinity.

The next vignette is about the process of applying the (ln ) to the function $\left(\frac{\cos x}{x}\right)$ geometrically. Observe that on the $x-$ axis as we approach 0 from the right the graph of $\frac{\cos x}{x}$ goes to infinity, so $\ln \left(\frac{\cos x}{x}\right)$ will also approach infinity but this time yielding lower graph than that of the function $\frac{\cos x}{x}$ ( $\left.\operatorname{since} \ln k<k\right)$. Also observe that $\ln$ is defined on the positive numbers, so in the interval $\left(\frac{\pi}{2}, \frac{3 \pi}{2}\right)$ the graph of the $\frac{\cos x}{x}$ is below the $x$-axis, hence, $\ln \left(\frac{\cos x}{x}\right)$ will have no graph in $\left(\frac{\pi}{2}, \frac{3 \pi}{2}\right)$. On the other hand, in the interval of $\left(\frac{3 \pi}{2}, \frac{5 \pi}{2}\right)$ the maximum value of the function $\frac{\cos x}{x}$ is less than 1 ; it is at the middle of the interval at $2 \pi$, the exact value of the $\frac{\cos x}{x}$ is $1 / 2 \pi<1$, so the value of $\ln (1 / 2 \pi)$ is negative, and all the values in the interval $\left(\frac{3 \pi}{2}, \frac{5 \pi}{2}\right)$ will have smaller $\ln (\cos x / x)$ values; observe that as we approach $\frac{5 \pi}{2}, \ln (\cos x / x)$ will go to minus infinity. The same processes are done as we approach $3 \pi / 2$ as $\cos x / x$ equals zeros at $3 \pi / 2$, and $5 \pi / 2$. This process will continue wherever the $\cos x / x$ is positive figure 9 . 


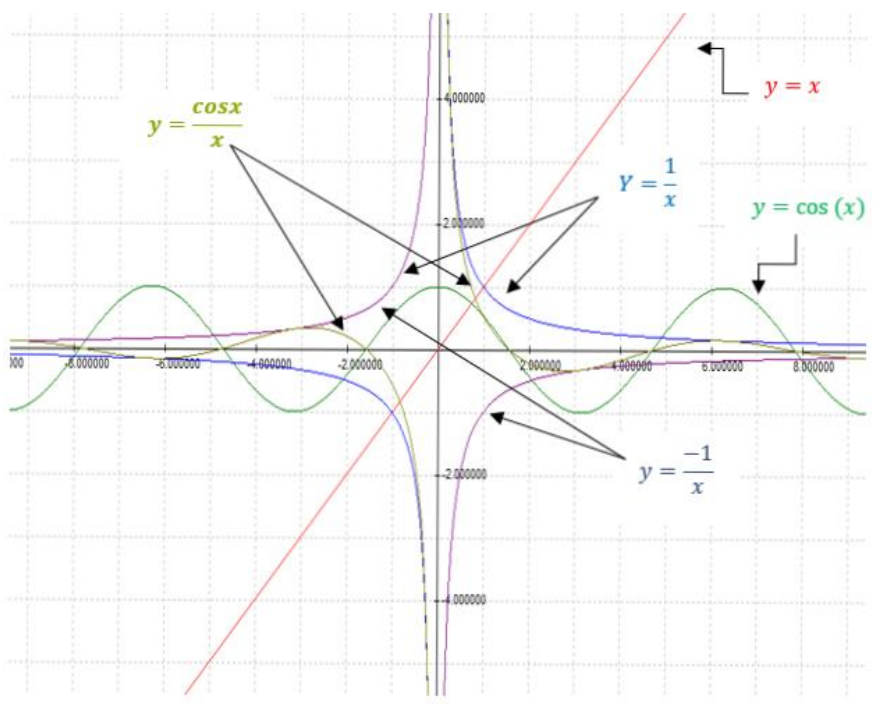

Fig. 8. $y=x, y=\cos x, y=\frac{1}{x}, y=-1 / x, y=\cos x / x$

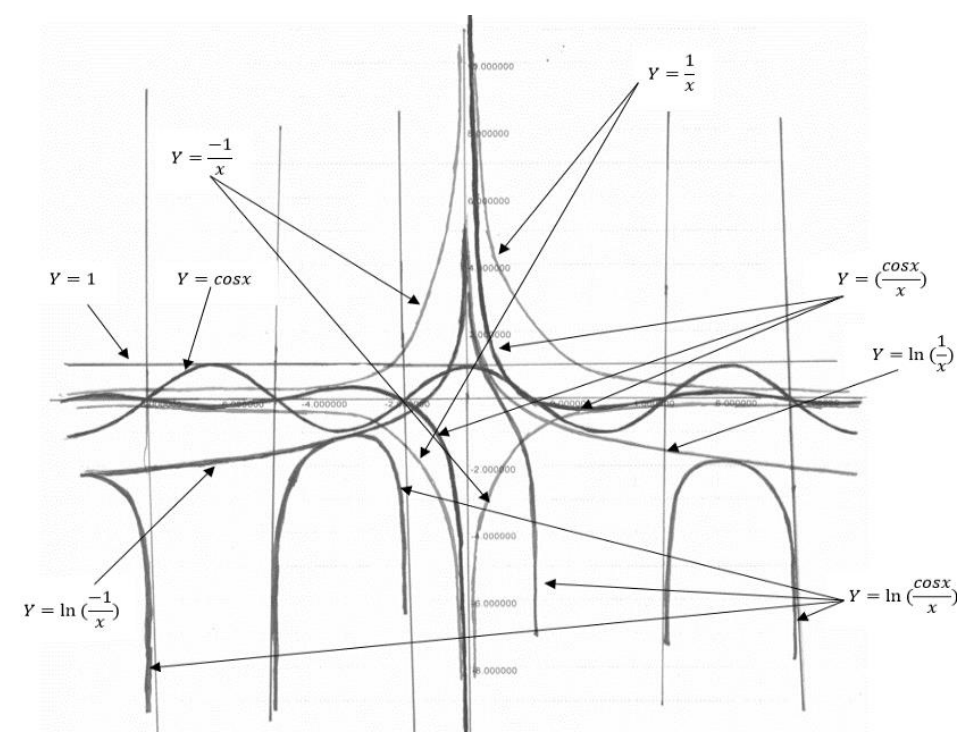

Fig. 9. $y=\cos x, y=1, y=\frac{1}{x}, y=-\frac{1}{x}, y=\frac{\cos x}{x}, y=\ln \left(\frac{1}{x}\right), y=\ln \left(-\frac{1}{x}\right), y=\ln \left(\frac{\cos x}{x}\right)$

Reflecting on the $\cos x / x$ you will discover that $1 / x$ is a floor on $(-\infty, 0)$ and as a ceiling on $(0, \infty)$. Similarly, $-1 / x$ is a ceiling on $(-\infty, 0)$, and is a floor on $(0, \infty)$. Since the maximum value for the cosine is (1) and the minimum value is $(-1)$. Therefore, it becomes logical to think of the graph for $\ln (1 / x)$ and $\ln (-1 / x)$ as a ceiling 
too. You will discover that the four functions are silent features, operating together to produce the graph of the function $f(x)=\ln \left(\frac{\operatorname{cox}}{x}\right)$ (figure 9).

As I was explaining my way of thinking, learners interrupted me several times to ask questions; they asked for justification for the reasoning. So, the interaction was highly interactive and responsive as they almost asked questions to clarify and reason every single move. As I approached the end of the class time, I gave them another example to demonstrate similar processes. At the end of this vignette several functions, ideas, and issues were raised and discussed, functions such as $\cos x, x, \frac{\cos x}{x}, \frac{1}{x}, \ln \left(\frac{1}{x}\right), \ln \left(-\frac{1}{x}\right), \ln \left(\frac{\cos x}{x}\right)$ and most importantly their interrelationships were analyzed and debated. The characteristics of these functions were deeply and purposefully discussed. We connected all those entities into a coherent and elegant representation as one schema among several other possible schemas.

Step3: To test the grasping of the idea of interrogation of silent feature, developing skills and disposition, I asked my students to graph a variety of functions.

\section{$4 \quad$ Results and Discussion}

\subsection{Student's responses and analysis}

Pre-observation responses: Students collectively were not able to graph any of the functions given in table1. One of the comments was made by a female student who openly said "asking us to graph such functions is just like giving a nonnative-English newborn child a Shakespearean novel text and asking her to analyze it". Many students whispered to each other and they also openly said "we really do not know how to graph these functions and if we need to find the derivative, it is going to be impossible for us to find the zeros of the first and second derivatives. All students became silent for a few moments after they had tried to draw the $x-$ axis and $y-a x i s$ and then they gave up. Some students drew sketches like those shown in figure 1 to figure 5 , and no one was able to provide a rationale for their sketches. There was no empirical data to collect and analyze quantitatively, simply because all students got a score of zero in the pre-observation trial.

Post-observation responses: I wrote $f(x)=\ln \left(\frac{\sin x}{x}\right)$ to start with, and students immediately responded by saying that "this function is trivial and similar to that graph; referring to the graph of $\ln \left(\frac{\cos x}{x}\right)$ except at $x=0$ the $\sin x / x$ is $1 "$. Then, they started drawing the $\sin x, x$, and slowly they composed $\sin x / x$; with negotiations, they started applying the $\ln$ to $\sin x / x$. In contrast to their previous responses shown in figures 1 and figures 5 where no mature understanding or functional sense was apparent, whereas, in this example, many students expressed verbally that they could sketch it. Several students were curious about the result of dividing zero by zero (0/0). They said, "we know it is 1 by applying the sandwich theorem, but how can we make sense of it". Nevertheless, as they continue the division process, they noticed that they are dividing values getting closer to each other as they were getting closer to $x$ equal 0 . They concluded by saying " thing/thing =1)", and explained why the values of the $\sin x$ and the values of the function $y=x$ are getting closer to each other, as $x$ is getting closer to 0 . This 
is a great achievement to make sense of why the $\lim _{x \rightarrow 0} \frac{\sin x}{x}=1$ other than the official proof by using the pinching theorem or sandwich theorem.

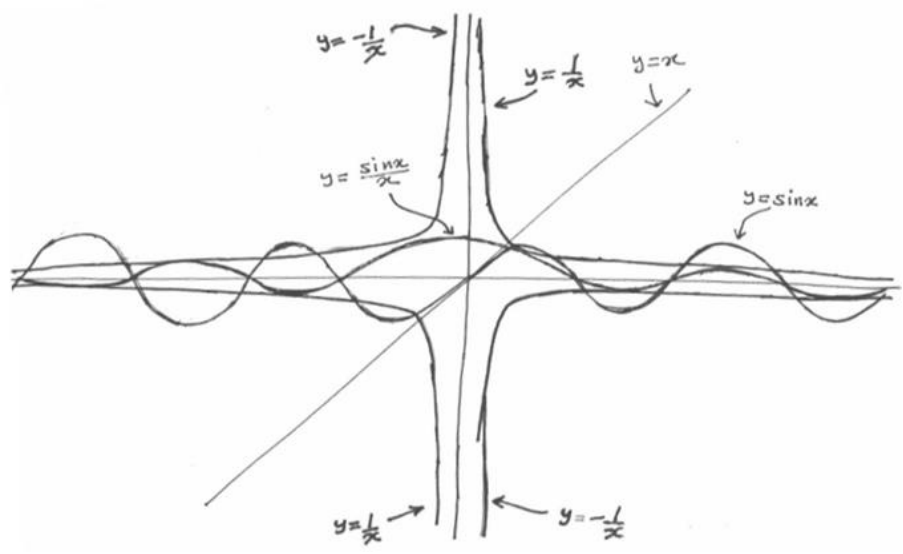

Fig. 10. $y=x, y=\sin x, y=\frac{1}{x}, y=-\frac{1}{x}, y=\sin x / x$

Moreover, students drew four functions in figure 10, then they detected two more functions (Figure 11); $\ln \left(\frac{1}{x}\right)$ and $\ln \left(-\frac{1}{x}\right)$, which are related to the function $\sin x / x$, and $\ln (\sin x / x)$. These functions are considered boundary for the functions $\sin x / x$, and $\ln (\sin x / x)$ respectively. These functions I will call them the silent ingredient for the function $\ln (\sin x / x)$. In the end, they became interested to explore more graphs, were amazed when they recognized the amount of information they had to deal with the complexity of the graph, and they were at the end able to graph it.

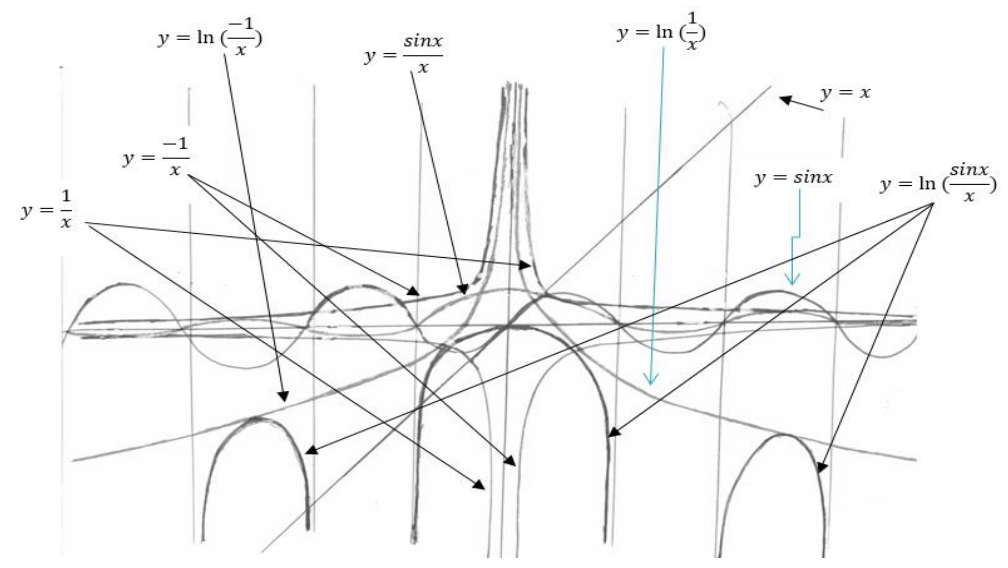

Fig. 11. Student's graphs for $y=x, y=\sin x, y=\frac{1}{x}, y=-\frac{1}{x}, y=\frac{\sin x}{x}, y=\ln \left(\frac{1}{x}\right), y=$

$$
\ln \left(-\frac{1}{x}\right), y=\ln \left(\frac{\sin x}{x}\right)
$$


In the next example was $f(x)=\cosh x$, the first move students did was that they asked, what is the $\cosh x$. I intentionally wrote on the board $\cosh x=\frac{e^{x}+e^{-x}}{2}$. They immediately draw $e^{x}$, and $e^{-x}$, and started to try to add values of both functions at chosen $x$ values and dividing them by 2 , some of them mentioned that it is like the average values for both functions. (figure 12).

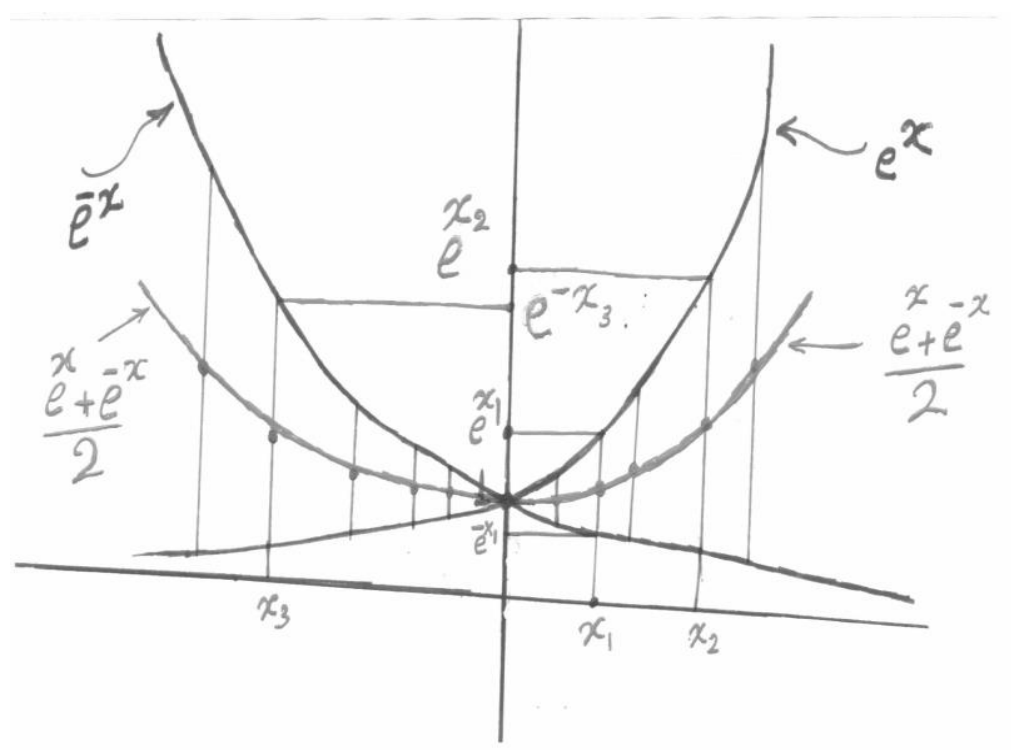

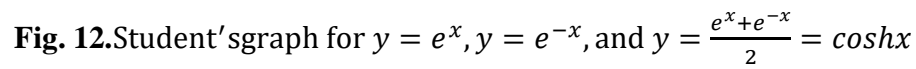

In the next activity, I asked them to try to sketch $f(x)=\ln (\sec x / x)$. Students started the activity by breaking the function into its smaller components: $\cos x, x, 1, x \cos x$ figure 13 , and then they draw them and started to make the multiplication and division processes. Even though they struggle in imagining and drafting the function $x \cos x$, but it was fascinating for them to discover that the function $y=$ $x$ is an asymptote. Likewise, for $y=-x$. They drew vertical asymptotes at the intersection of $x \cos x$ and $x$-axis; those zeros are the denominator of the function $1 / x \cos x$. Many of the students suggested comparing the graph of $1 / x \cos x$ with $1 / x$. Their reasoning for their suggestion was: $\cos x$ ranges between minus one and positive one, so $1 / x$ and $1 / x \cos x$ have common values (when $\cos x=1$ and -1 ). As soon as they discovered its relationship, they also suggested $y=(-1 / x)$ to discover similar relations. They discovered that $y=1 / x$ is a ceiling for $1 / x \cos x$ on $(\infty, 0)$, whereas, $1 / x$ is the floor for the same function on $(0, \infty)$. On the other hand, the function $(-1 / x)$ plays the same role but on the opposite interval figure 14 . 


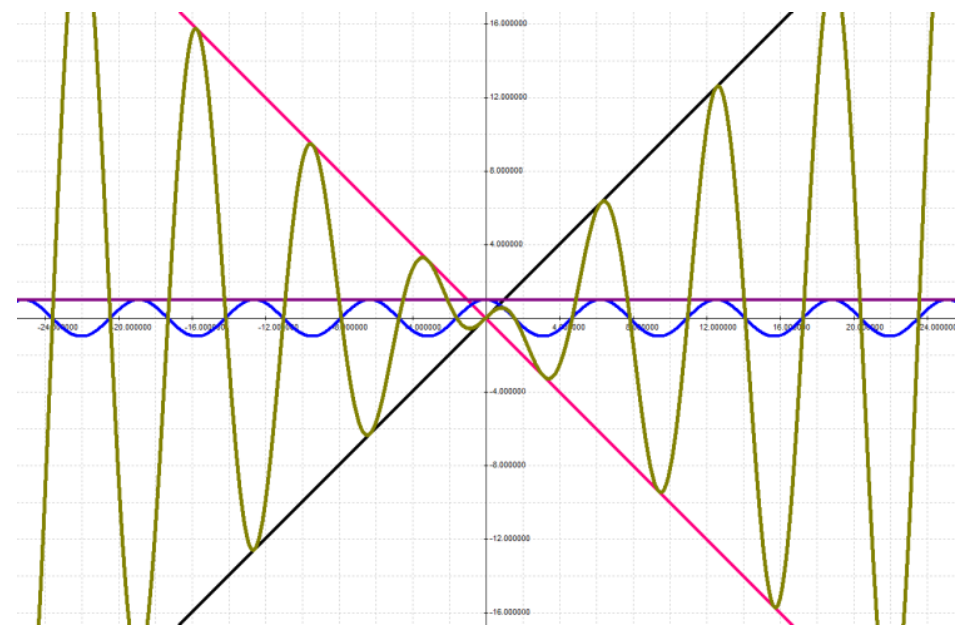

Fig. 13. $y=x, y=-x, y=1, y=\cos x, y=x \cos x$.

As a result of struggling and negotiation in applying the $(\ln )$ to the graph of $\left(\frac{1}{x \cos x}\right)$ figure 10 and to

achieve precision and elegance, they suggested that $\ln \left(\frac{1}{x}\right)$ and $\ln \left(-\frac{1}{x}\right)$ have common values with $\ln \left(\frac{1}{x \cos x}\right)$. They discovered that both functions are a floor for $\ln \left(\frac{\sec x}{x}\right)$, and graphed one fascinating picture shown in figure 15 .

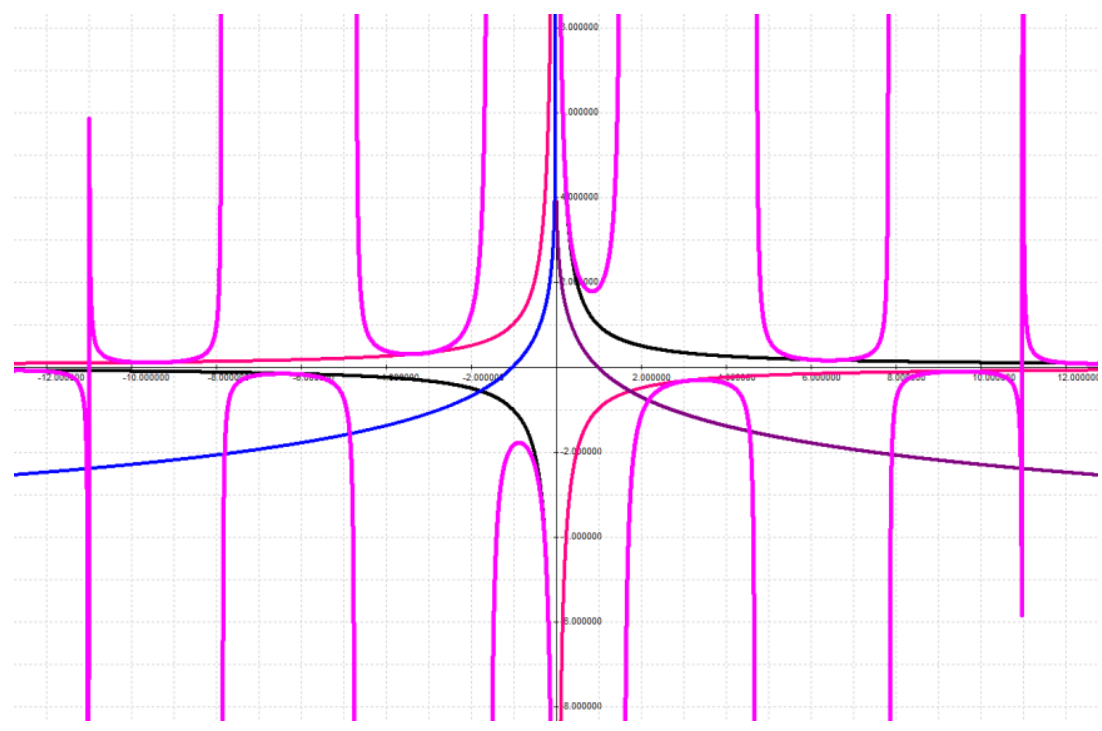

Fig. 14. $y=\frac{1}{x}, y=-\frac{1}{x}, y=\ln \left(\frac{1}{x}\right), y=\ln \left(-\frac{1}{x}\right), y=\left(\frac{1}{x \cos x}\right)$ 


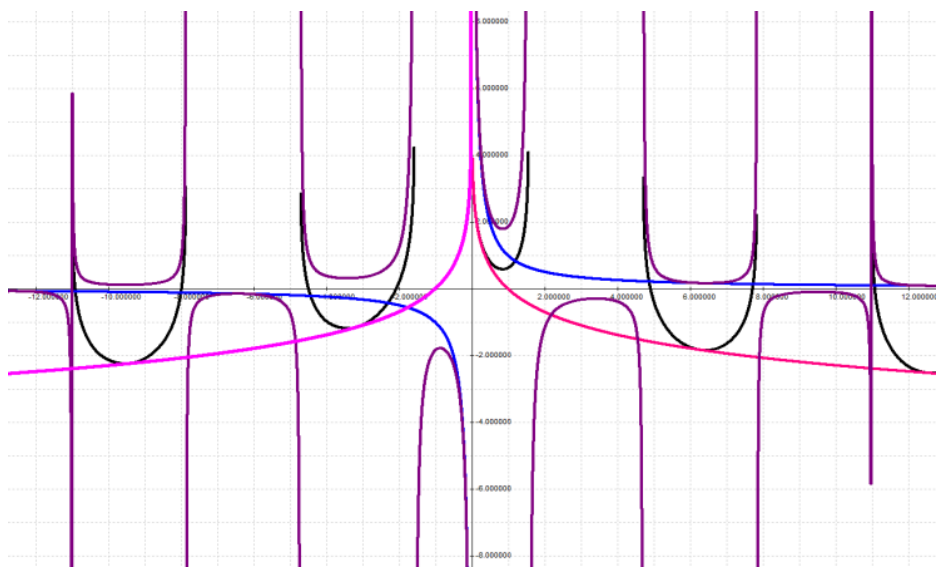

Fig. 15. $y=\frac{1}{x}, y=\ln \left(\frac{1}{x}\right), y=\ln \left(-\frac{1}{x}\right), y=\frac{1}{x \cos x}, y=\ln \left(\frac{1}{x \cos x}\right)$

At the end of their work, we summarized what had been done, and the interrelationships among all of the component functions were highlighted. The functions we used are: $y=x, y=-x, y=\cos x, y=1, y=$ $x \cos x, \frac{1}{x \cos x}, \frac{1}{x},-\frac{1}{x}, \ln \left(\frac{1}{x}\right), \ln \left(-\frac{1}{x}\right)$, and $\ln \left(\frac{1}{x \cos x}\right)$ (figure 16).

All are interconnected through creating connections among objects and among actions to produce such a complex schema through what Piaget called a "reflective abstraction. Producing elegant-even though it looks complex, and non-comprehendibleinterconnected graph requires a deep use of mental efforts, such as analysis, synthesis, imagination, hypothesizing, discussion, reversing, and manipulating three basic functions; $x, 1$, and $\cos x$. The use of all those mental efforts became possible to be used and invested through the interrogations of silent features.

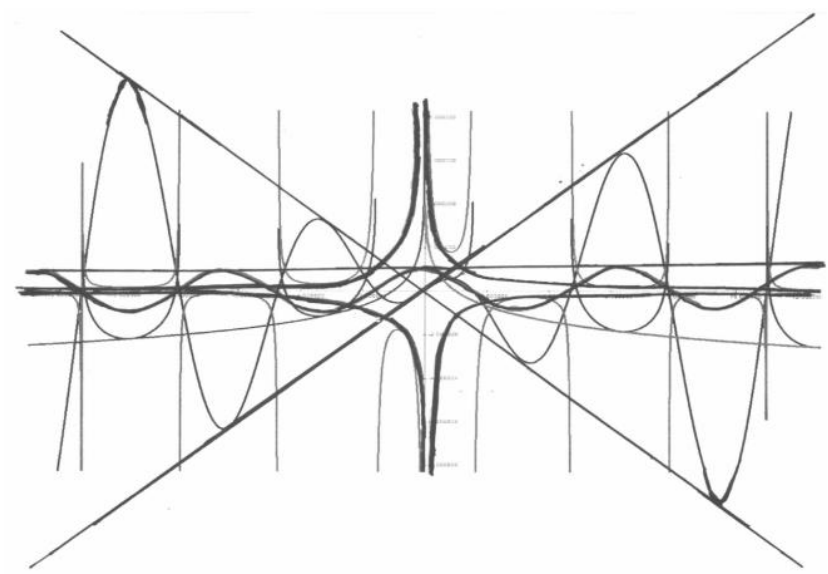

Fig. 16.Fig. 16. $y=\cos x, y=x, y=1, y=-x, y=x \cos x, y=\frac{1}{x}, y=-\frac{1}{x}, y=\frac{1}{x \cos x}, y=$ $\ln \left(\frac{1}{x}\right), y=\ln \left(-\frac{1}{x}\right), y=\ln \left(\frac{1}{x \cos x}\right)$ 
In the next function which it was $f(x)=\ln \left(\frac{x^{4}-1}{x^{3}}\right)$, students immediately start drawing $x^{4}-1$ and $x^{3}$ at the same coordinates (Figure 17), and start dividing geometrically; dividing the values of the graph on the denominator over the values of the graph on the numerator.

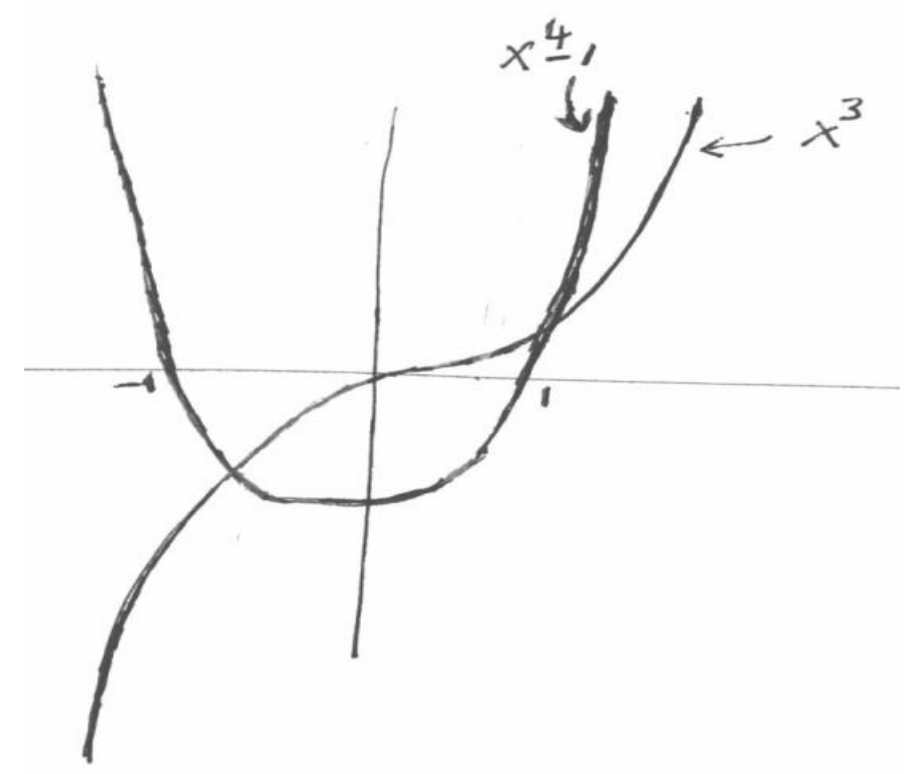

Fig. 17. $y=x^{4}-1, y=x^{3}$

They started the division process from $x=0$, immediately they began to think and reason in the following way: negative divided by positive and then dividing by 0 , this implies that the graph of $\frac{x^{4}-1}{x^{3}}$ has to approach minus infinity as we approach zero from the right. On the other hand, as we approach zero from left, we divide negative values by negative values (both functions are under the x-axis), so the result is positive and as we approach zero from left the graph goes to infinity. Finally, they graphed the function as a result of the division as shown in (Figure 18). 


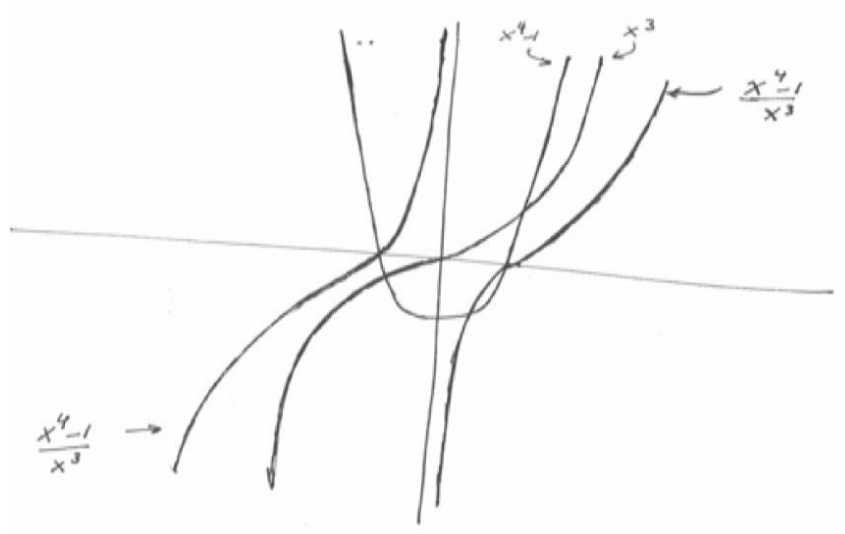

Fig. 18. $\mathrm{y}=x^{4}-1, y=x^{3}$, and $\mathrm{y}=\frac{x^{4}-1}{x^{3}}$

One of the students provided the following algebraic manipulation $\lim _{x \rightarrow \infty} \frac{x^{4}-1}{x^{3}}=$ $\lim _{x \rightarrow \infty}\left[\frac{x^{4}}{x^{3}}-\frac{1}{x^{3}}\right] \rightarrow x$ explaining that $\frac{1}{x^{3}} \rightarrow 0$ as the values of $x$ goes to $\infty$. Another student asks "what is the meaning behind the limit goes to $x$. As they drew $y=x$, they came up with the conclusion that the graph of $\frac{x^{4}-1}{x^{3}}$ should get closer to the graph of $y=x$ (Figure 19). As a result, they adjusted the graph of the function $\frac{x^{4}-1}{x^{3}}$ to be concave down and that $y=x$ as an oblique asymptote (Figure 19).

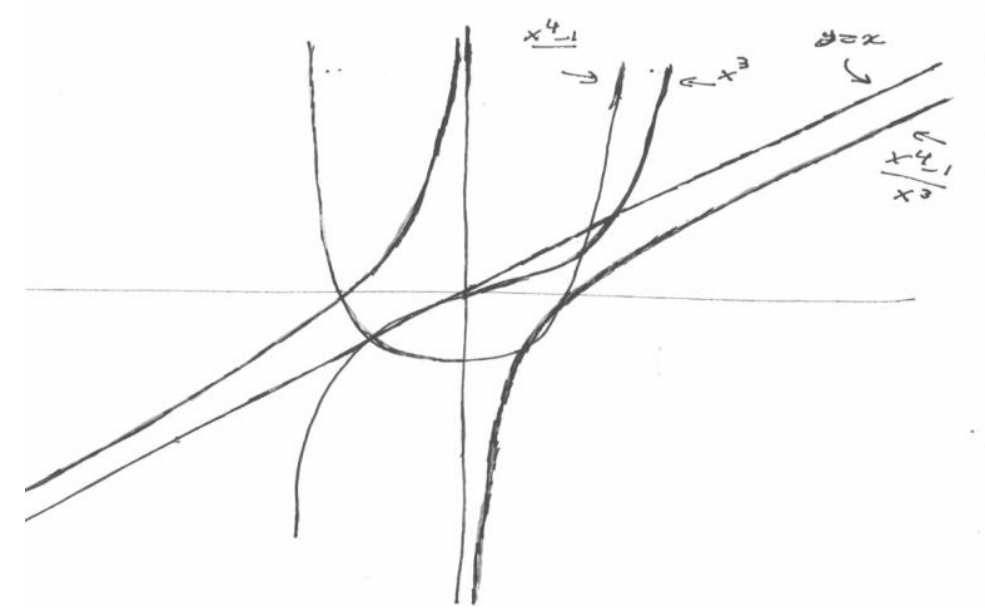

Fig. 19.Fig. 19. $y=x^{4}-1, y=x^{3}, y=x, y, y=\frac{x^{4}-1}{x^{3}}$ 
As they reach this point, they decided to apply the logarithm $(\ln )$ to the graph of $\frac{x^{4}-1}{x^{3}}$. They determined on the graph where the function $\frac{x^{4}-1}{x^{3}}$ approximately equals to 1 , and they concluded that $\ln (1)=0$. They also observed that the zeros of the function $\frac{x^{4}-1}{x^{3}}$ are the same as the zeros of the function $x^{4}-1$; They are -1 and 1 .

Also, they concluded that when the $\frac{x^{4}-1}{x^{3}}$ is negative (below the $x$-axis) on $(-\infty,-1]$ the logarithm is not defined. Hence, they concluded that no graph can be drawn. The same thing applies to the function on the interval $(0,1)$; the function $\frac{x^{4}-1}{x^{3}}$ is negative (below the $x$-axis). On the interval $[1, \infty)$ the graph is above the $x-$ axis, so the logarithm can be applied. At the values of $x$ where the function satisfies the inequality $0<\frac{x^{4}-1}{x^{3}} \leq 1$, the graph of $\ln \left(\frac{x^{4}-1}{x^{3}}\right) \leq 0$, students approximately identify the value on the $x$-axis such that the value of the function $\frac{x^{4}-1}{x^{3}}$ would equal 1. The graph increases as $x$ increases and will get closer to the graph of the function $y=x$, as $x$ goes to infinity. Making the same graph similar to the graph of $y=\ln x$. They ended up drawing the graph for the function $\ln \left(\frac{x^{4}-1}{x^{3}}\right)$ (Figure 20).

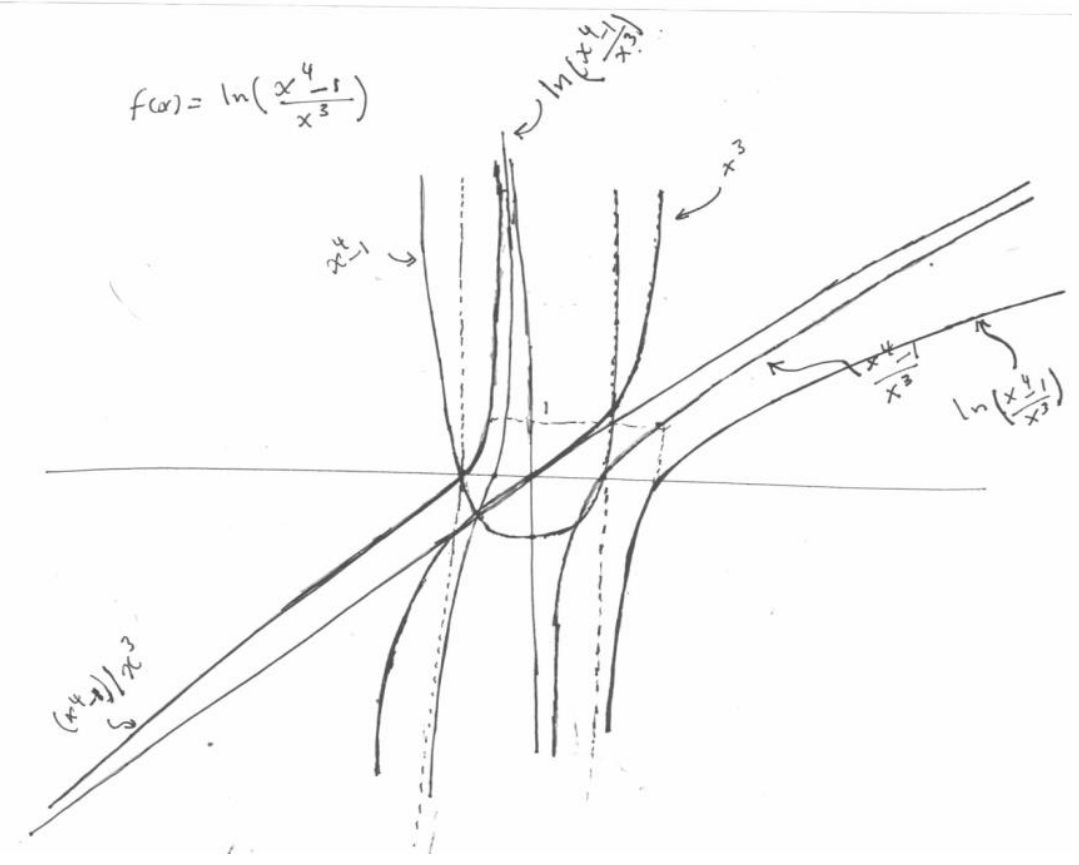

Fig. 20. $y=x^{4}-1, y=x^{3}, y=x, y=\frac{x^{4}-1}{x^{3}}$, and $y=\ln \left(\frac{x^{4}-1}{x^{3}}\right)$.

Both students and the researcher achieved successful end and breathtaking as they achieved overcoming the struggle through negotiation, discussion. Students' interac- 
tion and feedback were intense and investigational in nature. They corrected each other, reflected on each other ideas, and that their suggestions were carefully heard as they were thirsty for ideas and enlightenment.

Report of pre- and in-service teacher professional growth: Participants were asked to react by providing answers and feedback regarding their view toward this method, such as what did they learn and how they felt?

Some of the participants reported their appreciation for learning such a method. One participant said, "even though this method was strange and new because I never thought that would be possible to draw a graph without algebraic traditional manipulation, but when I tried to apply what I learned I soon discovered that I could draw, even though I did not reach a sophisticated level, but in comparison to the level where I was I am now much better, and what is good about this method is that it allows me to connect all the information related to the function to draw it".

Other participants said "this method has an impact on improving my understanding the domain, and how the components of the function can impact each other to determine the range. Furthermore, drawing is an actual and practical application to all the attributes of the function"

Another interesting feedback from a student was "it was difficult for me to graph functions because I used to see the function as a whole. I did not see its smaller components. but now as I get engaged in connecting the smaller components, I developed a functional sense. now I am better, I never did this before"

Other participants mentioned "it developed abstraction and reflection. Had teacher and students applied it continually, the science of mathematics would have developed faster, it broadens my vision and cognition of the interrelationships among function components and how I can draw a function if I recognize the silent features"

Other participant said "this method is a set of constructive steps. each step is an important block to build a mental structure"

other participant added, "I believe this is the best way to help students put together scatter and diffused information about many functions such as sine, cosine, and exponential functions, the traditional method did not allow observing how smaller components can be consolidated to form one whole complex graph".

Others talked about the importance of curriculum and the teacher's role" teacher specialized content knowledge is crucial in helping students build conceptual knowledge. This is a specialized content knowledge the teacher must acquire, and as a teacher that this knowledge gives me the confidence not to avoid student's questions that I am not prepared to answer, I feel I am prepared"

Other participants added "it helps us understand what is behind procedural work, and reorganize and mold it in a meaningful manner. Now, we can tell what certain curves tell us; referring to her ability to read and interpret graphs, now we have trust in ourselves to deal with a more complex function instead of resorting to the software to draw graphs blindly"

Another student said "what attracted me most is how silent feature has an unmated impact on the function, I feel confident that I can work with functions even complex one. before we used to have fear toward graphing functions. This method allows me 
to see things in more than one direction, now we can rotate our heads in all directions, my capacity to analyze is very much better"

The majority of the participants used terms such as "enjoyable, fabulous, brilliant, new, non-traditional" as a description of this method.

Participants reaction analysis: Several meanings can be deduced out of the participants' reactions. Students' feedback "this method allows me to see things in more than one direction, now we can rotate our heads in all directions" refers to cognition and flexibility enhancement in dealing with functions. This was due to the meaningful experience that they were exposed to. Through which they were able to build links and knowledge instead of scatters and diffused information. They also had the opportunity to interpret and understand what is behind the procedural work. It was manifested in their answer "understood what is behind procedure work" as well as in their feedback "we can read what curves try to tell us". Participants had developed self-dependent as compared to software-dependent in graphing functions blindly.

Besides, the participants' disposition was enhanced toward graphing functions and learning mathematics. Participants displayed interest, reflection, and appreciation that were clear through participants' feedback and answers. Students' curiosity was reflected as they posed specific questions and asked for clarification and reasoning.

They expressed the difference in their self-confidence for graphing functions before and after they learned this method. Their pre-observation comment "asking us to graph such functions is just like giving a nonnative-English newborn child a Shakespearean novel text and asking her to analyze it" and post-observation comments like "this function is trivial and similar to that graph; referring to the graph of $\ln \left(\frac{\cos x}{x}\right)$ except at $x=0$ the $\sin x / x$ is $1 "$ reflects-beside other things- reflects the difference in attitude and confidence in themselves. Their self-efficacy has improved significantly; It was clear as they asked for more challenging functions. Last but not least, they felt what they learned through this method is a specialized content knowledge that would empower them as teachers and that their role would be more effective in helping their students to be better learners.

\section{Summary}

Through reflective discussion, individual interaction, as well as student-student interaction, the level of understanding, had improved gradually from the empirical abstraction to pseudo-empirical abstraction. Reflective abstraction improved gradually as participants started to verbally explain and describe to each other how the smaller components of the function may impact the whole graph. At the end of the meeting time, students were amazed by the wonderfulness of all those relationships. After all the struggle and negotiation, happiness and confidence on their faces were obvious. Some of them even suggested trying more graphs of their own, which was an indication for positive disposition and a sign of readiness and confidence to deal with even more complex functions or phenomena. This result is what educators struggle to achieve.

The pedagogical view for the method of interrogation of silent ingredient can be rationalized through encouraging students to focus on investing student's basic related 
knowledge in a novel way to explore inter-relationships to produce and build a significantly more complex structured schema. Moreover, it provides a serious challenge to students to operate higher-order cognitive thinking creatively. Cooperation and collaborations were the mediums through which analysis was made, hypotheses were examined, and connections were explored.

\section{Conclusion}

This innovative method of interrogation silent ingredients provides a novel opportunity for students to invest their prior knowledge, mathematical reasoning and cognitive strategies as they were analyzing complex functions into smaller pieces. Such functions are hard to graph through finding the derivatives, where the derivations processes become missy; it was extremely difficult to employ due to the complications of the derivation of complex functions. This method has the potential to lend itself to students to help them deal with such complexity.

The result of this study suggested that students' ability and disposition to graph complex functions are enhanced. Moreover, it provides students with alternative means to make sense of complex functions through using and analyzing what they already knew.

In many instances, students said, "now we understand why the graph has a vertical asymptote or horizontal and its meaning, or why a graph is concave up or downward". So, this novel method serves to enhance understanding of mathematical concepts through sense-making.

Furthermore, for the teacher, this method could be used as an assessment mean for students' prior knowledge. This is because this method is based on students' ability to apply basic knowledge to operate basic functions that are either divided by each other or multiply by each other or added to each other or composition of functions; in which function is used as a domain of another function. It assesses students' ability to identify and deal with critical points in the non-traditional approach, and it assesses students' ability to apply all of these processes geometrically. The method of interrogation silent ingredients can be used as a search engine for a deficit in knowledge. I also believe this fresh and non-traditional approach just like learning analytic [22] can be added to teacher repertoire in which provide teachers as an expert the flexibility needed to intervene at not just at the zone of proximal development [23] but also at the inside and outside of the zone of proximal development [24] in any way possible; according to learner's need to provoke highly intellectual discussion and experiences that may benefit learner. This method is metaphorically similar to the interactive technology either computer software or tablets or smart digital technology [12] through which every single function provides learners with a situation in which they will have to employ combinations of several critical thinking skills and a proper pedagogical approach to help facilitate learning achievement [25]. Besides, the use student's prior knowledge, student has to analyze the components of the function; how smaller functions are combined; then they have to decide - among many choices what path and course of action can serve them better; then they have to hypothesize 
how the impact resulted from applying certain operation among the smaller components may look like; translate the algebraic expression and operations into sub-graph, and then judge and evaluate the outcome resulted from applying certain operation. Such overt and covert engagement positively enhances the quality of student's learning.

\section{$7 \quad$ Recommendation}

Based on this research result and observation, the researcher recommends that teachers and researchers can utilize this method and adapt it into their repertoire of teaching methods through their instructional design to enhance students' ability and disposition toward mathematics in general and toward graphing skills in particular, as well as a mean for assessment. Moreover, the knowledge related to such a method can be viewed as a specialized content knowledge that may empower secondary mathematics teachers.

Toward this end, I provide this analysis as a catalyst for reflection and as a forum debate.

\section{$8 \quad$ References}

[1] B. Sriraman, and L. D. English, "Theories of mathematics education: A global survey of theoretical frameworks/trends in mathematics education research," ZentralblattFür Didactic der mathematik, vol. 37, no. 6, pp. 450-456, 2005. https://doi.org/10.1007/bf0265 $\underline{5853}$

[2] L. Edward, "Gestures and conceptual integration in mathematical talk," Educational Studies in Mathematics, vol. 70, no. 2, pp. 127-141, 2009.

[3] J. I. Acevedo, "Phenomena related with the use of metaphors in teachers' discourse," Doctoral dissertation, University of Barcelona, Barcelona, Spain, 2008.

[4] V. Font, "An onto-semiotic perspective on four instruments of knowledge that resemble a family: Particular/general, representation Metaphor and context," Education Matematica, vol. 19 no. 2,pp. 95-128, 2007.

[5] O. Robutti, "Motion, technology, gesture in interpreting graphs," International Journal of Computer Algebra in Mathematics Education, vol. 13, 117-126, 2006.

[6] V. Font, and J. "Acevedo, Phenomena related with the use of metaphors in teachers' discourse the case of graphs of functions," Enseñanza de las. Ciencias, vol. 21 no. 3, pp. 405418, 2003.

[7] L. Bazzani, "From grounding metaphors to technological devices: A call for legitimacy in school mathematics," Educational Studies in Mathematics, vol. 47, no. 3, pp. 259-271, 2001.

[8] S. Papadakis, M. Kalogiannakis, and N. Zaranis, "Improving mathematics teaching in Kindergarten with realistic mathematical education," Early Childhood Education Journal,vol. 45, pp. 369-378, https://doi.org/10.1007/s10643-015-0768-4.

[9] S. Papadakis, "The effectiveness of computer and tablet assisted intervention in early childhood students' understanding of numbers. An empirical study conducted in Greece," Education and Information Technologies, vol. 23, no. 5, pp. 1849-1871, 2018. https://doi. org/10.1007/s10639-018-9693-7 
[10] M. Kalogiannakis, S. Papadakis, “Evaluating pre-service kindergarten teachers' intention to adopt and use tablets into teaching practice for natural science" Int. J. Mobile Learning and Organization, vol. 13, no, 1, pp. 113-127, 2019. https://doi.org/10.1504/ijmlo.2019.1 $\underline{0016617}$

[11] S. Papadakis, "Evaluating pre-service teacher acceptance of mobile devices with regards to their age and gender: a case study in Greece," International Journal of Mobile Learning and Organization, vol. 12, no. 4, pp. 336-352, 2018. https://doi.org/10.1504/ijmlo.2018.10 $\underline{013372}$

[12] S. Papadakis, M. Kalogiannakis, M. Zaranis, "Comparing tablets and PCs in teaching mathematics: An attempt to improve mathematics competence in early childhood education," Preschool and primary Education, vol. 4, no, 2, pp. 241-253, 2016a. https://doi.org/1 $\underline{0.12681 / \text { ppej. } 8779}$

[13] A. Sierpinska, Understanding mathematics. Bristol, PA: The Falmer Press-Taylor \& Francis Inc, 1994.

[14] M. Ben-Hur, Concept-Rich Mathematics Instruction: Building a strong foundation for reasoning and problem solving. Alexandria, VA. Association for Supervision and Curriculum Development (ASCD), 2006.

[15] E. Dubinsky, and G. Harel, Eds., The Concept of Function: Aspects of Epistemology and Pedagogy. U. S. A.: The mathematical Association of America, 1992.

[16] M. Swan, "Dealing with misconceptions,"in Issues in Mathematics Teaching, P.Gates, ed. NY: Routledge Falmer, pp. 147-165, 2001.

[17] J. Piaget, Structuralism. New York: Basic Books, 1968.

[18] I. Arnon, J. Cottrill, E. Dubinsky, A. Oktac, S. Fuentes, M. Trigueros and K. Weller, APOS Theory: A framework for research and curriculum development in Mathematics Education. New York: Springer Science + Business media, 2014. https://doi.org/10.1007/9 78-1-4614-7966-6_7

[19] E. Dubinsky, "Reflective abstraction in advanced mathematical thinking," in Advanced mathematical thinking, D. Tall, Ed. New York: Kluwer Academic Publishers, pp. 95-123, 1991. https://doi.org/10.1007/0-306-47203-1_7

[20] A. Moore, Understanding The School Curriculum. New York: Routledge, 2015.

[21] E. Glazer, Using Internet Primary Sources to Teach Critical Thinking Skills in Mathematics. CT: Greenwood Publishing Group, Inc., 2001.

[22] N. Vidakis, A. K. Barianos, A. M. Trampas, S. Papadakis, M. Kalogiannakis, and K. Vassilakis, "Generating education in-Game Data: The Case of an Ancient Theatre Serious Game," In Proc. Of the 11th International Conference on Computer Supported education (CSEDU), B. mclaren, R. Reilly, S. Zvacek and J. Uhomoibhi, Eds., Crete, Greece: Heraklion, vol. 1, pp. 36-43, 2019. https://doi.org/10.5220/0007810800360043

[23] L. S. Vygotsky, Mind in society: The development of higher psychological processes. Cambridge, MA: Harvard University Press, 1978.

[24] P. Del Rio, and A. Alvarez, "Inside and Outside the zone of Proximal Development: An Ecofunctional reading of Vygotsky," in The Cambridge Companion to Vygotsky, H. Daniels, M. Cole, and J. Wertsch, Eds. Cambridge: Cambridge University Press, pp. 276-304, https://doi.org/10.1017/ccol0521831040.012.

[25] P. Dorouka, S. Papadakis, and M. Kalogiannakis, "Tablets and apps for promoting robotics, mathematics, STEM education and literacy in early childhood education," Int. J. Mobile Learning and Organization, vol. 14, No. 2, pp. 255-274, 2020. https://doi.org/10.1504/ ijmlo.2020.10026334 


\section{Author}

Muad M. Shiyyab, obtained his Ph.D. in mathematics education from the University of Texas At Austin worked as an assistant professor in the department of mathematics at the University of Philadelphia. Currently working at Yarmouk University in the college of education teaching both mathematics course and mathematics education courses. He focuses his research on mathematics learning, curriculum, pedagogy of mathematics as well as specialized content knowledge for teaching mathematics. $\mathrm{He}$ is the author of the secondary mathematics training program for the Queen Rania Academy. (Email: muadhh@yahoo.com).

[26]

Article submitted 2019-09-14. Resubmitted 2020-02-07. Final acceptance 2020-02-07. Final version published as submitted by the authors. 